tions emerge, and we can perhaps expect McKinney to pursue these in future writings.

On broad historiographical grounds, however, there are two grave defects in this book. The first is McKinney's unconsidered approach to the way religion and science interacted in the nineteenth century. He cites the historian Hooykass ("religion $\rightarrow$ science") favourably, but elsewhere couches his descriptions of Wallace in terms that overstress his own ahistorical biases: Wallace was "essentially unprejudiced by religious preconceptions"; "unencumbered by religious ties", and so on. This language is too value-laden.

Secondly, McKinney seems to be wholly unaware of the social and political contexts of evolutionary biology. Some of the very material he cites patently indicates Wallace's early meritocratic view-a view which needed the philosophical (and psychological) support provided by natural selection theory. McKinney does not catch this.

Nor does he seem to know of recent work by $\mathrm{R}$. M. Young and others on the specific ideological backgrounds of Chambers, Malthus, Darwin and Wallace himself. Natural selection was such a useful political tool, and arose at such an opportune time, that it is hard to believe its originators were unmotivated by "external" (that is, non-scientific) factors. The single external factor in McKinney's book (aside from religion, which he mishandles) is Wallace's ambition. Otherwise, McKinney concentrates only on intellectual motives, and though he does this very well, the resulting explanation is insufficient for modern history.

It is as if by reading Vestiges, Lyell and Malthus, spurning religion and dabbling in natural history (which is all Wallace did at first), anyone could have hit on a mechanism of evolution, perhaps natural selection itself. Yet hundreds of intelligent men did just these things (in spite of McKinney's denial - unfootnoted - of widespread atheism) without such results. So what really did happen that led Wallace to this grand theory?

As yet, Dr McKinney has provided only a fraction of the answer. Because he is such a fine scholar, however, we must hope that he can widen his view.

J. R. FRIDAY

\section{Atmosphere of Stars}

Basic Physics of Stellar Atmospheres. By T. L. Swihart. Pp. viii +86 . (Pachart: Tucson, 1972.) \$7.95.

THIS is a short text covering the theory of stellar atmospheres for the nonspecialist. It consists of four chapters covering the equation of transfer and formal solutions thereof, the grey atmosphere, model atmospheres and line formation. An appendix summarizes physical and astronomical constants and presents a number of exercises.

The book seems inferior to other recently offered stellar atmosphere texts. The aspects of the field treated in any detail exclude any of the important recent developments. For example, while the Avrett-Krook temperature correction procedure is derived in some detail there is nowhere mentioned the linearization methods developed by Auer and Mihalas which will soon displace the above procedure in essentially all aspects of model building.

The author explains in the preface that his approach is basically physical as opposed to mathematical. By this he apparently means that he includes specifically the microscopic physics that go into the radiation transfer process. In so far as he carries that philosophy the derivations and discussions of the input physics are very clear and readable. Yet I am amazed at the almost complete absence of a discussion of continuous absorption processes. A novice reading this as an introduction to the field would be left with the impression that essentially the only relevant source of continuous opacity is that of the $\mathrm{H}^{-}$ion. The possibility of neutral hydrogen as a source of opacity is mentioned in only two sentences in the entire book. The neutral hydrogen absorption cross-section is never presented and the idea of opacity discontinuities is completely missing. This is somewhat surprising in that perhaps the most important aspect of model stellar atmospheres is their ability to predict the continuous spectra of stars and how they depend on temperature and gravity.

The lack of discussion of the macroscopic aspects of the physics of stellar atmospheres is also disturbing. Very few concrete results are given. What are typical densities in the photospheres of $B$ stars and of $M$ stars? What are the electron donors across the $\mathrm{H}-\mathrm{R}$ diagram? Where is $\mathrm{H}^{-}$important? Neutral hydrogen opacity? Molecular opacity? In short we find the discussions to be rather sterile and far more mathematically oriented than implied in the author's preface.

The execution of this book also leaves something to be desired. Different faced typing is often slightly displaced below the rest of the text which is disconcerting. The only two illustrations are interchanged. The rather thick covers contribute almost half of the total thickness of the book.

This book is the first of a series of "Intermediate Short 'Texts in Astrophysics" to be published by the author and his colleague, A. G. Pacholczyk.
As with any "first", there are many lessons that can be learned here.

\section{M. Peterson}

\section{Mycology from India}

Hyphomycetes: An Account of Indian Species, except Cercosporae. By G. V. Subramanian. Pp. $x i+930$. (Indian Council of Agricultural Research: New Delhi, 1971.) Rs.50.

Professor G. V. Subramanian is an acknowledged expert on the Hyphomycetes and a book by him dealing with this difficult group is to be welcomed. On opening the book it is, however, something of a disappointment to find that, although the publication date is 1971 , the monograph was prepared in 1961 and contains no references to publications later than 1962. In view of the attention given to this group in the last decade by mycologists all over the world, including the outstanding contributions made by Professor Subramanian himself and his students, it is to be hoped that the publishers will give him the opportunity of bringing it up to date in the near future.

The first part (some 180 pages) gives an informative account of the early work on Hyphomycetes, of their general structure, habitats and importance in industry and agriculture, and discusses heterocaryosis, classification and nomenclature. In view of the author's own critical studies the section on classification is of particular value. A clear account is given of attempts up to 1961 to formulate a more natural arrangement than Saccardo's system which, while useful as a means of identification, brings together obviously unlike organisms in the same genera. Professor Subramanian adopts a system based on those of Hughes and Tubaki but gives his own definition of spore types. Since during the last decade there have been a number of other discussions and criticisms of the Hughes/Tubaki suggestions it is particularly unfortunate that this book does not contain Professor Subramanian's own more recent modifications of the system he proposed in 1961. It does, however, offer a firm basis for appreciation of recent contributions. This general section concludes with a useful bibliography of work published before 1962 .

The greater part (Part II) of the book is devoted to descriptions of all species of Hyphomycetes recorded in India up to $1961 / 2$, amounting to over 500 species. Necessary additions to and revisions of this part to bring it up to date are likely to be relatively unimportant. Part II begins with a useful key to genera and at appropriate places in the text keys are given to Indian species of each genus. Full and clear 